\title{
Cultural Differences In Learning And Implications For Distance Delivery Of Educational Programmes To Developing Nations: A Case Study In Fiji.
}

Morris W. Shanahan, (Email: shanahanm@cpit.ac.nz), Christchurch Polytechnic Institute of Technology, New Zealand

\begin{abstract}
Shanahan (2006) found that to be effective the delivery of distance learning programmes to developing nations had to overcome certain constraints, such as cultural constrictions (i.e., issues of language), tradition-based limitations (i.e., paternalistic and hierarchical structures), an inherited past (colonialism), and poor infrastructure (particularly in relation to telecommunications). It was argued that all of these obstacles needed to be managed and sufficiently overcome if distance delivery was to be of any utility. This study builds upon this research to include possible differences in learning styles across cultures that may influence the functionality of web-based distance learning programmes. Fiji was chosen as a useful case study as this country has a population that is almost evenly split between two cultures: indigenous Fijians and people of Indian ancestry who were born in Fiji. These people were submitted to the same integrated educational systems, governmental processes, economic constraints, and social norms and laws. Participants in this study completed the Lincoln VARK Learning Styles Questionnaire ${ }^{l}$ and comparisons were made between learning styles and by ethnicity, age, computer access, and job position. Results indicated no significant difference in learning styles between cultures, but significant differences between learning styles across the total sample were evident. The results suggest learning differences need to be taken into account if maximum outcomes are to be achieved from web-based distance learning programmes. Such a finding has ramifications for educational institutions offering distance learning curriculums as the poor completion rates may partly be a function of not moderating such programmes to cater to the differences in learning styles. It is simply not a totalitarian process.
\end{abstract}

Keywords: distance learning, cultural differences, learning styles, computer access, distance education.

\section{INTRODUCTION}

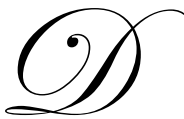

istance education has been identified by many as an increasingly preferred educational option and potentially the future of education (Galusha, 1997; Rumble, 2001; "Lifelong", 2002; Howell, Williams \& Lindsay, 2003; Makoe, 2006; Neidorf, 2006). But it is not without problems, both in the design and delivery of learning programmes. Impediments such as diminished motivation (Galusha, 1997), lack of a strong internal locus of control (Parker, 1999), poor monitoring systems (Jin, 2005), cultural differences (BanutuGomez, 2002), greater opportunities for miscommunication (Ragan \& White, 2001), restraints on communication capabilities (Schuler \& Rogovsky, 1998), life circumstances (Kemp, 2002), and, in relation to developing nations, lack of resources and infrastructure deficiencies (Shanahan, 2006) and social rigidity issues (Hutakau, n.d.), all

\footnotetext{
${ }^{1}$ Copyright Version 7.0 (2006) held by Neil D. Fleming, Christchurch, New Zealand and Charles C. Bonwell, Green Mountain Falls, Colorado 80819 U.S.A
} 
influence the ability of students to successfully negotiate distance learning programmes. While Howell, Laws, and Lindsay (2004) argue, with some justification, that comparisons between distance and traditional face-to-face programmes are problematic, it must still be considered best practice to provide educational curriculum that affords the greatest number of students the opportunity to successfully complete.

Over the past few years traditional educational institutions have become increasingly aware of the need to enhance revenue opportunities and the exportation of learning programmes has grown exponentially. Domestic as well as foreign markets have been cultivated. However, the trend has been mainly to modify traditional face-to-face programmes for distance delivery rather than examine the needs of distance learners and generate suitable learning programmes to meet their specific needs (Castañeda, 2005). This study examines just one aspect of the need for specificity - the learning styles of individuals in a developing nation - The Republic of Fiji. Is distance delivery a simple case of 'one size fits all', or do educators need to be cognizant of the need to tailor distance learning programmes to meet the needs of specific and distinctive groupings?

\section{BACKGROUND}

There is currently plenty of support for the need to match educational delivery methods and learning styles to achieve optimum learning outcomes for students (Dunn, 1986; Bajtelsmit, 1990; Hutton, 1998; Atherton, 2005; Fahy \& Ally, 2005; Manochehri \& Young, 2006: Shanahan, 2006; Villaverde, Godoy \& Amandi, 2006). This appears to be particularly true for distance learning methods (Chernish, DeFranco, Lindner \& Dooley, 2005). But Galusha (1997) argues that distance learning "requires a collaborative effort between student and teacher, unbounded by traditional limits of time, space, and single-instructor effort." ( $\mid 5)$, and, as mentioned above, that distance learners must deal with additional impediments specific to the individual's learning environment (Zuhairi, Wahyono \& Suratinah, 2005). Simply modifying existing programmes for web delivery may not be fulfilling these criteria. Possibly as a result, dropout of distance learning programmes is significantly higher than on campus counterparts (Kember, 1990/1995; Eastmond, 1992; Parker, 1999; Brady, 2001). Kember (1995) suggests that high dropout rates for distance courses may be in part due to a lack of attention given to the differences in learning styles of students. Hutton (1998) goes further, arguing that “...it [dropout rates] is a reflection of distance education's inability to date to cater for differences in individual's abilities and styles of providing course with teaching styles that match or meet the needs of all students." (p.9). For example, she found that many distance learners needed high levels of structure to the programme, the near opposite of the expectations of self-directed, independent learners.

In relation to learning styles and distance education, Fleming and Bonwell (2001) state that as the Internet is dominated by text "One would expect that those with some preference for the read/write mode would appreciate ...the ease of access of text on the screen." (p.39). Fleming and Bonwell were supported by the findings of Fahy and Ally (2005) who discovered that some learning styles "may be disposed to greater participation" (p.17) than others in regard to distance education. However, note that Pate-Moulton, Klages, Erickson and Conforti Jnr (2004) argued that writing is not a strength for all learners and that Internet learning that utilises e-mail for example may suffer from the narrowness of the communication band with a significant loss of emotional connectedness that may be important to particular individuals (Shanahan, 2006). Indeed, for many learners the more structured $\mathrm{read} / \mathrm{write}$ learning style may be highly inappropriate. While classroom delivery can still cater for a variety of learning styles through multi-modal teaching techniques (visual, kinaesthetic, aural), web-based delivery is more problematic, particularly in developing nations where the Internet suffers poor penetration, lack of bandwidth and the ability for interactivity, and high consumer cost. As a result, many in these nations are simply not able to access the more multi-modal distance programmes available to their Western counterparts and are often restricted to e-mail as the basic mode of distance communication. This in itself is problematic (Shanahan, 2006).

\section{Exporting Education To Different Cultures}

Changes in the educational environment has forced institutions to be far more revenue conscious and externally focused than ever before. Institutions are now looking to mass produced programmes (Hutton, 1998) as the differentiation between for-profit and non-profit institutions becomes more ambiguous (White, 2003). In New Zealand, as with many other Western countries, the search for student growth has had to shift off-shore with the 
delivery of distance programmes to countries with different languages, religious affiliations and ethnic constructions. But there have been few cross-cultural comparisons (Zualkerman, Allert and Qadah, 2007) to ascertain the efficacy of the exportation of web-based distance programmes. As Howell, Williams and Lindsay (n.d.) suggest, distance learning requires a pedagogical shift with more emphasis on the student as an independent, self-motivated learner which, as Shanahan (2006) implies, may not necessarily suit all cultures. As Dunn and Griggs (1995) state "Culture influences both the learning process and its outcomes." (p.37). While, as Howell et. al, suggest distance learning may provide the boost in revenue required by educational institutions to overcome funding challenges, the exportation of educational programmes may need to be tailored to meet the specific needs of the particular cultures. McCool (2006) agrees suggesting that a "streamlined and minimalist linear information structure [as inherent in most Westernized distance programmes] excludes numerous cultural requirements for many international audiences." (p.335). Design and delivery of many distance programmes does not appear to suitably meet the needs of distance learners in developing nations as the delivering institutions are not adequately considering the student's needs nor the restraints of reception and usability of distance programmes. It may simply not be a case of 'one-size fits all'. This study examines the audiences in one such developing nation.

\section{Fiji As A Case Study}

Fiji provides a unique opportunity to explore learning styles and distance learning. Firstly, the country is emerging as the most developed in the South Pacific region with a relatively stable and working infrastructure and economic base. Secondly, Fiji's population comprises two distinct cultural groups; indigenous Fijians who make up approximately 54\% of the population, and Fijians of Indian descent (Indo-Fijians) comprising 41\% (Fiji Islands Bureau of Statistics, Retrieved 27 February 2007 at http://www.statsfiji.gov.fj/). Both populations live and work together, share a common social and educational grounding, observe the same laws, and function in the same economic climate. However, they also both maintain their own cultural integrity. Indo-Fijians tend to be predominantly Hindustani while Fijians are strongly Christian; each group celebrates their own cultural festivals and holidays; each possesses an independent identity that relates strongly to their particular ancestry as well as their stake in Fiji. As Hutakau (n.d.) states, "Their way of life is like a form of 'social poetry' with imagery and metaphor everywhere."

Considering the unique cultural, behavioural and physical environments apparent in a developing nation such as Fiji, several possibilities are evident. Firstly, Zualkerman, Allert and Qadah (2007) found that despite huge cultural differences between Middle Eastern and American students, there were no significant differences in learning styles. This supports earlier conclusions made by Dunn and Griggs (1990) who argued that individuals exhibit different learning styles within cultures and even within families. If, as suggested, the shared educational experience, strong relationships to being 'Fijian' irrespective of ethnicity and/or religion, and a shared experience of a British colonial past, then;

H(1) there will be no significant differences in learning styles between cultural groups.

However, Pacific Island history and traditions are passed from generation to generation in a visual/oral manner, through discussion and active, visual presentations (Hutakau, n.d.) and students "display behaviours that reflect the culture in which they live" (Sims and Sims, 2006, p195). This is true for both major ethnicities in Fiji. It can therefore be argued that both ethnic groups will exhibit preferences for aural and visual learning styles with a lesser preference for a kinaesthetic learning style, and that reading/writing should be the least favoured. Therefore;

H(2) differences will exist between learning styles with reading/writing being the least favoured.

It can be further argued that the common educational experience, economic egalitarianism, and homogeneity in knowledge and understanding in such a small, sheltered country as Fiji should result in;

H(3) no significant differences in learning styles as a result of age, Internet access or job position. 


\section{METHOD}

The VARK Learning Styles questionnaire designed originally by Fleming and Mills (1992) was distributed to 209 employees of two businesses in Suva, Fiji. Both businesses were selected for their high level of computerization, a strong corporate belief in the continuing training of all employees, and ease of access. Questionnaires were distributed to all available employees on a Monday morning. All participants were instructed to return their completed questionnaires to the researcher at a set time on the following Friday. The cover sheet dealt with the ethical considerations of the research which also had approval from the CPIT research committee. The questionnaire also sought information on ethnicity, age, Internet access and job position. Of the 209 questionnaires distributed, 153 were returned (73\%) of which $12(6 \%)$ had not been properly completed and had to be discarded. Final overall usability was $68 \%$.

The VARK questionnaire was selected due to its ability to discriminate between learning styles that have significant relevance to the Fijian population, namely aural and visual categories, as well as relevance to distance delivery with the reading/writing category. It is also a simple and easy to administer test that does not take a great deal of time for participants to complete - an important factor in gaining access. Once completed and returned, the results were entered into an SPSS spreadsheet for analysis. Dependent variables were the four learning styles and categorical variables were age, ethnicity, access to email and job position. Categorical variables were dummy coded 0 or 1 , with 1 representing membership in the category. A variety of tests were conducted to assess the multiplicity of hypotheses and relevant results were exhibited in table form.

\section{Limitations}

This study does not represent a randomly-selected population and any extrapolation of results to the wider Fijian and/or any other populations must be made with caution. Secondly, this study lacks a control mechanism making any comparatives with other cultures tenuous.

\section{RESULTS}

Table 1 exhibits percentage of participants by age, ethnicity, computer access and position. Note that only $21 \%$ of participants had access to email at home. This is significantly less than that in most developed nations. In addition $37 \%$ only had access to email at work on a computer that was shared with at least one other individual. However, as expected, nearly all participants had access to email in one form or another.

Table 1: Percentage of participants by age, ethnicity, computer access and position

\begin{tabular}{|c|c|c|c|}
\hline Participants & $\mathbf{\%}$ & Participants & $\mathbf{\%}$ \\
\hline 15-24 years of age & 21 & Email access on shared computer at work only & 37 \\
\hline 25-34 years of age & 45 & Email access on personal computer at work only & 38 \\
\hline 35-44 years of age & 22 & Email access at home only & 0 \\
\hline 45+ years of age & 11 & Email access at work and at home & 21 \\
\hline Fijian & & Email access at Internet café only & 4 \\
\hline Indo-Fijian & 49 & Part-time employee & 4 \\
\hline Other & 42 & Full time employee & 79 \\
\hline No Access to email & 9 & Supervisor & 5 \\
\hline
\end{tabular}

One way ANOVA for dependent variables Visual (V), Aural (A), Reading (R), and Kinaesthetic (K) showed a significant difference $(p<0.01, F=4.71, d f 3,137)$ between variables. A simple $t$-test to identify any significant differences from chance are exhibited in Table 2 confirming that both $\mathrm{V}$ and $\mathrm{K}$ were significantly above chance, $\mathrm{R}$ was significantly below chance and A showed no significant difference. 
Table 2: One-sample t-test of dependent variables results from chance

\begin{tabular}{|c|c|c|c|c|}
\hline \multicolumn{5}{|c|}{ Test Value = Chance } \\
\hline & $\mathbf{t}$ & df & Mean Difference & Sig. (2-tailed) \\
\hline Visual & 7.170 & 140 & 1.152 & .001 \\
\hline Aural & 1.042 & 140 & .145 & .299 \\
\hline Reading & -23.322 & 140 & -2.294 & .001 \\
\hline Kinaesthetic & 6.551 & 140 & 1.025 & .001 \\
\hline
\end{tabular}

Between variables ANOVA results showed significant differences between learning styles. $\mathrm{V}$ and $\mathrm{K}$ were significantly different from both $\mathrm{A}$ and $\mathrm{R}$ while $\mathrm{V}$ was significantly different from $\mathrm{K}$ as well. Results indicate that the sample clearly exhibited preferences for $\mathrm{V}$ and $\mathrm{K}$ learning styles (see Table 3 ).

Table 3: ANOVAs between learning styles by total sample

\begin{tabular}{|c|c|c|}
\hline Conditions $(\boldsymbol{d} \boldsymbol{f} \mathbf{3 , 1 4 0})$ & $\boldsymbol{F}$ & $\boldsymbol{p}<$ \\
\hline Visual/Aural & 4.53 & 0.01 \\
\hline Visual/Reading & 3.95 & 0.01 \\
\hline Visual/Kinaesthetic & 4.89 & 0.01 \\
\hline Aural/Reading & 0.54 & 0.82 \\
\hline Aural/Kinaesthetic & 5.79 & 0.01 \\
\hline Reading/Kinaesthetic & 4.06 & 0.01 \\
\hline
\end{tabular}
$n=141$

Very few other significant differences were found. These are listed in table 4. Note that the supervisor and Internet café only samples were very small ( $n=7$ and $n=5$ respectively).

Table 4: Other significant ANOVA results

\begin{tabular}{|c|c|c|c|}
\hline Significant results & $d f$ & $F$ & $p<$ \\
\hline Supervisors were more A & 1,140 & 9.02 & 0.01 \\
\hline Those with their own work computer were more $\mathrm{R}$ & 1,140 & 7.36 & 0.01 \\
\hline Those with their own work computer were more $\mathrm{K}$ & 1,140 & 15.63 & 0.01 \\
\hline Those with Internet café only access were more K & 1,140 & 18.08 & 0.01 \\
\hline
\end{tabular}
$n=141$

Pearson bivariate correlation analysis turned up some further significant findings. Of particular interest was the finding that 'Others' were more likely to have access to computers both at work and at home $(r=.25, n=141$, $p<0.01)$. Other findings showed that managers were more likely to be aged between 25-34 or 35-44 ( $r=.28, n=141$, $p<0.01$ and $r=.41, n=141, p<0.01$ respectively), either share a work computer or have Internet access at work and at home $(r=.28, n=141, p<0.01$ and $r=.31, n=141, p<0.01$ respectively). Indo-Fijians were more likely to use an Internet café ( $r=.27, n=141, p<0.01)$ than Fijians or 'Others'. Supervisors who tended to be more aural were more likely to be in the $45+$ age group $(r=.33, n=141, p<0.01)$.

\section{DISCUSSION}

While the findings confirm the hypothesis (H1) that there would be no differences in learning styles between cultures, the results only partially confirm H2. Findings showed a distinct and significant preference for V and $\mathrm{K}$ learning styles over $\mathrm{A}$ and $\mathrm{R}$, and a preference for $\mathrm{V}$ over $\mathrm{K}$. The suggested cultural relevance of the aural 
traditions did not eventuate, but results did confirm a significant aversion to $\mathrm{R}$ as a learning choice when compared to $\mathrm{V}$ and $\mathrm{K}$. This raises several issues.

\section{Issues Facing Web-Based Distance Providers}

For a web-based distance programme to be successful Zuhairi, Wahyono and Suratinah (2005) argued that providers of distance education to developing nations must focus on understanding the very specific needs and constraints on learners. Shanks (2005) believes that distance programmers must engage learners in the Fijian environment to stimulate their kinaesthetic and visual learning modalities - i.e., get them 'doing' as opposed to reading/listening, an argument supported by the findings of this study. But too much of what is currently being included in distance education programmes appears to be mono-cultural with little specificity to the prospective enduser. It appears that providers simply must be cognizant of the specific needs of the learners they are targeting. This can only be accomplished in conjunction with an in-depth knowledge of the differences in learner needs, cultural constraints, and learning styles that exist. It is therefore imperative that web-based distance developers understand the variability inherent between themselves and the countries to which they intend delivering their programmes. Indeed, this may even be relevant within countries should a multiplicity of ethnic groups be the intended learners. Perhaps this accounts for the discrepancies that exist in dropout rates by ethnicity in the US.

It is also important to ensure user motivation and enthusiasm is kept high to reduce dropout. Hutakau (n.d.) suggests this is possible in Pacific Island cultures if content is based around issues and problems with direct relevance to the constraints inherent within the given society. Hutakau (n.d.) found support from Shanahan (2006) when he discovered that the executives he was working with in Fiji responded better to actual real-life problems rather than to theoretical discussions. This was irrespective of cultural background. But for these issues to be recognised and utilised requires an in-depth understanding of each specific group being catered for, including acknowledgement of particular learning styles. It may be incumbent upon providers to ensure the necessary research is conducted prior to design, development and delivery of distance learning programmes.

"The development of distance education depends on the existing level of information and communication technologies." (Moiseeva, 2005, p.225), something distance education providers must acknowledge and overcome if successful learning outcomes are to be achieved. In Fiji for example, as in many developing nations, a poor telecommunications infrastructure where Internet provision is highly limited and still extremely slow by most Western standards (Shanahan, 2006), the ability of distance education suppliers to deliver programmes in anything other than the reading/writing modality is decidedly restricted. This study found that approximately $80 \%$ of all participants in this study did not have Internet access at home, while just over half only had access to a non-shared computer terminal (either at home and/or at work). The obvious problem for those delivering distance programmes is that over $50 \%$ of this non-representative sample, with far better than average computer penetration in their work environments, would have the technology to even partake in web-based distance education, and over $60 \%$ would have to utilise access other than at home.

This raises a number of issues relating to privacy, employer support, time management, access, and tutor assistance. And this picture is an optimistic one. With close to $80 \%$ of the Fijian and nearly $90 \%$ of the Indo-Fijian population seen as economically disadvantaged (Robertson \& Sutherland, 2001) the actual access to web-based distance education would be much lower. Simply stated, Fiji does not have the technological infrastructure in place to support widespread web-based distance learning. The exportation of text-oriented, web-based distance programmes to learners in developing nations may more be in fulfilment of institutional financial imperatives rather than the educational necessities that exist in developing countries.

Finally, the results of this study partially confirm that there are no significant differences in learning styles as a result of age, Internet access or job position. While some differences were apparent, sample sizes were relatively small and further research would be required to confirm such claims. However, the finding that those participants with their own work computer were more likely to be R or K than those without their own computer access at work, raises some interesting possibilities. Does computer utilisation in such a constrained environment actually foster a more reading/writing and/or kinaesthetic learning style? Or are learners with a more $\mathrm{R}$ or $\mathrm{K}$ 
learning style more likely to find themselves in positions that provide computer access? Either way, it could be argued that the knowledge gap that exists between developed and developing nations will only continue to widen until technology reaches equitable levels across borders and access is more widespread. This is certainly an area in need of further investigation.

\section{Possible Solutions}

To be effective, web-based distance developers may need to adjust content to engage the visual and kinaesthetic modalities of all Fijians while minimizing the textual content in relation to theory. Shanahan (2006) serendipitously discovered that using text in a storytelling manner was useful in fostering visual images in his participants. He also discovered that relating real issues with relevance to the participant in story form and giving the individual action tasks also perpetuated learning, even when the information was delivered electronically via email. Perhaps designers of distance programmes may need to adjust their approach away from theory-based education to provide learners in countries like Fiji with a textual delivery method that enhances the visual and kinaesthetic modalities of learning.

Drop out rates may be reduced by ensuring there is more feedback delivered in modes more aligned with the learning style and cultural needs of the learner. This may require providers to embrace a more individualistic approach to web-based communication strategies based on in-depth knowledge of each participant, rather than the more broad-based approach common with much of distance education.

Limitations of e-mail can be at least partially overcome, as suggested by Shanahan (2006), through extension of the medium to incorporate the needs of the individual and his/her particular needs as a learner. Longer, less perfunctory e-mails appear to assist in overcoming at least some of the constraints of e-mail communication. This however does take more time and tutorial resource and can be difficult across cultures where language in particular may be a major barrier.

Finally, deliverers of web-based distance programmes may also need to assist in supplying the technological resources necessary to ensure success. This may include both hard and software as well as training on both. Indeed, it may also require assistance in building infrastructure that supports such learning programmes. Both are certainly problematic in most developing nations where political and economic stability may be in question. However, without the necessary tools for reception, there is little point in designing for delivery.

These suggestions may result in obvious financial and resource constraints which could jeopardize some programmes, a debate between finance and education which is yet to be resolved. But as educational institutions move further down the corporate road, it is certainly a debate that needs attention. If, as the results suggest here, exportation of web-based distance programmes to a relatively forward developing nation such as Fiji is fraught with problems of delivery, reception, utilisation and compatibility, then perhaps the paradigm requires shifting to better meet the demands and needs of potential consumers.

\section{CONCLUSION}

Attempts to export Westernized learning programmes to culturally varied developing nations may be guilty of not providing for the culturally specific learning styles of the target audience. To be truly effective, distance programmes must afford learners the opportunities to learn in their favoured modalities, firstly as a culture and then as an individual within that culture. It appears that any attempt to introduce lineal, highly structured distance educational programmes with a reliance on reading and writing is not in the best interests of the learners of Fiji or the providing institution. The key for web-based distance providers is to find ways to deliver such programmes in the preferred learning modality or modalities within the constraints of the society in which the prospective students live.

Castañeda (2005) argues that distance education needs to overcome "social, economic and cultural distances" (p.232) if it is to be successful as a mechanism for quality education to citizens in the multiplicity of 
global cultures. Firstly, it may need to overcome a Western mindset that fails at times to recognise the constraints existent in most developing nations and, secondly, as Dhurbarrylall (2005) suggests, develop a holistic, integrated approach to distance education that recognizes the needs of the people and that will provide education to the "deprived, marginalized, disaffected disadvantaged, and those who have not had a chance in the conventional education structure" (p.196). Thirdly, it may be necessary to address the gaps in technology between nations if advances in distance education are to be successful in under-developed countries. As the gap between developed and developing parts of the world widens, it will be vital for distance education developers to remember that 'one size does not fit all'. Maybe it is time to re-think the paradigm.

\section{REFERENCES}

1. Atherton, J. S. (2005). Learning and Teaching: Experiential Learning [On-line] UK: Retrieved 20 Feb 2007 at http://www.learningandteaching.info/learning/experience.htm

2. Bajtelsmit, J. W. (1990). In M.G. Moore (ed.) Contemporary issues in American distance education. New York, NY: Pergamon Press. 181-191.

3. Banutu-Gomez, M.B. (2002). Leading and managing in developing countries: Challenge, growth and opportunities for twenty-first century organisations. Cross Cultural Management, 9(4), 29-42.

4. Brady, L. (2001). Fault lines in the terrain of distance education. Computers and Composition, 18. 347-358.

5. Castañeda, M.M. (2005). A history of distance education in Mexico. The Quarterly Review of Distance Education, 6(3), 227-232.

6. Chernish, W.N., DeFranco, A.L., Lindner, J.R., and Dooley, K.E. (2005). Does it matter? Analyzing the results of three different learning delivery methods. The Quarterly Review of Distance Education, 6(2), 8795.

7. Dhurbarrylall, R. (2005). Development of distance education in Mauritius. The Quarterly Review of Distance Education, 6(3), 185-197.

8. Dunn, R. (1986). Learning styles: link between individual differences and effective instruction. North Carolina Educational Leadership, 2(1), 3-16.

9. Dunn, R. and Griggs, S.A. (1995). Multiculturalism and Learning Style: Teaching and Counselling Adolescents. Westport, Connecticut: Praeger.

10. Dunn, R. and Griggs, S.A. (1990). Research on the learning style characteristics of selected racial and ethnic groups. Journal of Reading, Writing, and Learning Disabilities, 6(3), 261-280.

11. Eastmond, D. V. (1992). Learning approaches of adult students taking computer conferencing courses. Paper presented at the Annual conference of the Northeastern Education Research Association. Ellensville, New York. 28 October 1992.

12. Fahy, P.J. and Ally, M. (2005). Student learning style and asynchronus computer-mediated conferencing (CMC) interaction. The American Journal of Distance Education, 19(1), 5-22.

13. Fleming, N.D. and Bonwell, C.C. (2001). How Do I Learn Best. Christchurch, New Zealand; Fleming/Bonwell.

14. Fleming, N.D. and Mills, C. (1992). Not another inventory, rather a catalyst for reflection. To Improve the Academy, Vol. 11. 137.

15. Galusha, J.M. (1997). Barriers to learning in distance education. [On-line] US: Retrieved 20 February 2007 at http://www.infrastruction.com/barriers.htm

16. Howell, S.L., Laws, R.D., and Lindsay, N.K. (2004). Re-evaluating course completion in distance education: avoiding the comparison between apples and oranges. The Quarterly Review of Distance Education, 5(4), 243-252.

17. Howell, S.L., Williams, P.B., and Lindsay, N.K. (2003). Thirty-two trends affecting distance education: an informed foundation for strategic planning. [Online] US: Journal of Distance Learning Administration, 6(3), Retrieved 20 February, 2007 at http://www.westga.edu/ distance/ojdla/fall63/howell63.html

18. Hutakau, I. F. (n.d.). A multicultural approach to learning: Pacific Island students. Retrieved online 20 October 2005 at http://alex.edfac.usyd.edu.au/ AcrossCurric/Paradise/M.H's\%20\%20ParaProb.html\#a\%20concept\%20of \%20time.

19. Hutton, J.L. (1998). The Learning Styles of First Year Distance Education Students. Lower Hutt, New Zealand: Open Polytechnic of New Zealand. 
20. Jin, S. H. (2005). Analyzing student-student and student-instructor interaction through multiple communication tools in web-based learning. International Journal of Instructional Media, 32(1), 59-67.

21. Kember, D. (1990). The use of a model to derive interventions which might reduce drop-out from distance education courses. Higher Education, 20, 11-24.

22. Kember, D. (1995). Open Learning Courses for Adults: A Model of Student Progress. New Jersey: Educational Technology Publications.

23. Kemp, W.C. (2002). Persistence of adult learners in distance education. The Quarterly Review of Distance Education, 16(2), 65-81.

24. Lifelong Learning Trends: A Profile of Continuing Higher Education. $7^{\text {th }}$ Edition. (2002, April). University Continuing Education Association.

25. Makoe, M.Q. (2006). South African distance students' accounts of learning in socio-cultural context: a habitus analysis. Race, Ethnicity \& Education, 9(4), 361-380.

26. Manochehri, N., and Young, J.I. (2006). The impact of student learning styles with web-based learning or instructor-based learning on student knowledge and satisfaction. The Quarterly Review of Distance Education, 7(3), 313-316.

27. McCool, M. (2006). Adapting e-learning for Japanese audiences tutorial. IEEE Transactions on Professional Communication, 49(4), 335-345.

28. Moseeva, M. (2005). Distance education in Russia: between the past and the future. The Quarterly Review of Distance Education, 6(3), 217-225.

29. Neidorf, R. (2006). Teach Beyond Your Reach: An Instructors Guide to Developing and Running Successful Distance Learning Classes, Workshops, Training Sessions and More. CyberAge Books. 248.

30. Parker, A. (1999). A study of variables that predict dropout from distance education. [On Line] US: Retrieved 20 February 2007 at http://smi.curtin.edu.au/ijet/v1n2/parker/index.html

31. Pate-Moulton, S., Klages, C., Erickson, A., and Conforti Jnr., P. A. (2004). Integrating technology and pedagogy: the DLP (Distance Learning Partners) project investigates literature circles. Curriculum and teaching dialogue, 6(1), 25-34.

32. Ragan, T. J. and White, P. R. (2001). What we have here is a failure to communicate: The criticality of writing in online instruction, Computers and Composition, vol 18, pp. 399-409.

33. Robertson, R and W Sutherland 2001, Government by the Gun: The Unfinished Business of Fiji's 2000 Coup, Pluto Press, Sydney.

34. Rumble, G. (2001). Re-inventing distance education, 1971-2001. International Journal of Lifelong Education, 20(1/2), 31-43.

35. Schuler, R.S. and Rogovsky, N. (1998). Understanding compensation practice variations across firms: The impact of national culture. Journal of Business Studies, 29(1), 159-178.

36. Shanahan, M. W. (2006). Outsider influence and the utility of e-mail as an instrument for teaching in developing nations: A case study in Fiji. College Journal of Teaching and Learning. 3(5), 1-12.

37. Shanks, R.C. (2005). Lessons in Learning, e-Learning, and Training. San Francisco, USA: Pfeiffer.

38. Sims, S.J., and Sims, R.R. (2006). Learning styles, de-contextualized testing, and the need for styleswitching in minority students. In R.R. Sims \& S.J. Sims (eds.) Learning Styles and Learning. New York, New York: Nova Science. 191-209.

39. Villaverde, J.E., Godoy, D., and Amandi, A. (2006). Learning styles' recognition in e-learning environments with feed-forward neural networks. Journal of Computer Assisted Learning, 22(3), 197-206.

40. White, L. (2003). Deconstructing the public-private dichotomy in higher education. Change, 35(3). 48-54.

41. Zualkerman, I.A., Allert, J., and Qadah, G.Z. (2007). Learning styles of computer programming students: a Middle Eastern and American comparison. IEEE Transactions in Education, 49(4), 443-451.

42. Zuhairi, A., Wahyono, E., and Suratinah, S. (2005). The historical context, current development, and future challenges of distance education in Indonesia. The Quarterly Review of Distance Education, 6(3), 95-101. 
NOTES 